\title{
Induction Motor DTC Performance Improvement by Reducing Flux and Torque Ripples in Low Speed
}

\author{
Yassine Zahraoui ${ }^{1 *}$, Mohamed Akherraz ${ }^{2}$, Chaymae Fahassa ${ }^{3}$, Sara Elbadaoui ${ }^{4}$ \\ 1,2,3,4 Mohammed 5 University, Mohammadia School of Engineering, Rabat, Morocco \\ Email: ${ }^{1}$ zahraoui.yassin@gmail.com, ${ }^{2}$ akherraz@emi.ac.ma, ${ }^{3}$ fahassa.chaymae@gmail.com, ${ }^{4}$ elbadaouisara@gmail.com \\ ${ }^{*}$ Corresponding Author
}

\begin{abstract}
Since induction motors were invented, human civilization has changed forever. Due to their beneficial characteristics, induction motors are widely used and have become the most prevalent electrical counterparts. Many control strategies for induction motors have been developed, varying from scalar to vector control. In the class of vector control, the Direct Torque Control (DTC) was proposed as an alternative that ensures separated flux and torque control while remaining completely in a stationary reference frame. It offers direct inverter switching, reasonable simplicity than other vector control techniques, and less sensitivity to parameter variation. However, the use of hysteresis controllers in conventional DTC involves non-desired ripples in the system's flux and torque, which leads to bad system performances, primarily in low-speed operations. This paper aims to minimize the chattering and ensure the augmented system's performance in terms of robustness and stability. The proposed method is an improved version of DTC, which combines the addition of the Space Vector Machine (SVM) algorithm to the DTC and the increased number of DTC sectors that generate reference control voltages. Satisfactory results have been obtained by numerical simulation in MATLAB/Simulink. Eventually, the proposed method is proven to be a fast dynamic decoupled control that robustly responds to external disturbance and system uncertainties, especially in the low-speed range.
\end{abstract}

Keywords-Induction motor drive; Space vector modulation; Twelve sectors DTC; Total harmonic distortion; Flux distortion; Torque pulsation; Harmonic reduction

\section{INTRODUCTION}

Since induction motors were invented, the trajectory of human history has changed. Even now, the century-old motor, firstly designed by the famous scientist Nicola Tesla, is the most prevalent motor type. Induction motors account for around half of all global electric power use. They are built and designed for practical simplicity, unlike any other electrical counterparts; permanent magnets are unneeded, mostly are brushless, and have no commutator rings or position sensors [1]. Induction motors are also capable of self-starting operations. The most significant advantage of induction motors is that their speed can be easily changed by modifying the power frequency. They are a good fit for elevators, cranes, and even electric cars because of this feature [2]. Electric automobiles can operate in a single-speed transmission due to the high-speed band of induction motors [3]. Another noteworthy feature is that they can also operate as a generator when a prime mover moves the rotor. Thus, it is critical to ensure that the rotating magnetic field speed is always lower than the rotor speed in this scenario [4].

The vector control, also known as field-oriented control (FOC), was developed to circumvent the limitations of scalar control [5] [6]. It was introduced in the 1970s, designed to provide independent torque and flux control comparable to the separate excitation DC machine [7] [8] [9]. FOC has some drawbacks; one of FOC's fundamental drawbacks is the coordinates transformation. The coordinates transformation requires the flux angle, which cannot be directly measured. Another drawback is related to the machine's sensitivity while there are changes in machine parameters such as stator and rotor resistance [10]. Meanwhile, Direct Torque Control (DTC) is another way that ensures separated flux and torque control. In the middle of the 1980s, Takahashi and Noguchi first introduced it to Japan. Unlike FOC, this control technique is carried out entirely in a stationary frame (stator fixed coordinates). Furthermore, DTC generates the inverter gating signals directly through a look-up switching table and does not require any modulator [11]. Although DTC has fewer model parameters than FOC, it provides a better response regarding the torque. In other words, DTC is simpler and has a profoundly fast response. Hence, it is suitable for high-performed drive applications [12].

Unfortunately, hysteresis in the fundamental DTC method causes undesired ripples in flux and torque [13]. Some modifications and improvements of DTC have been made, aiming to lessen the ripples. When the Space Vector Modulation (SVM) was proposed as an alternative solution to this issue, the study results proved its functionality [14]. Despite its complexity, this method reduces the high level of ripples [15]. Meanwhile, the number of sectors to generate the reference control voltages is also considered efficient to tackle this problem [16]. Study findings found that the twelve sectors of DTC resulted in good dynamics while the system is being operated in the high and low-speed ranges [17] [18] [19]. In summary, the proposed method combines the advantages of both FOC and DTC while eliminating their drawbacks. 
The research aims to control and improve the performance of an induction motor drive system by modifying the DTC using a robust and nonlinear technique. The research can be summarized into two stages: 1) The high torque and flux ripples will be minimized by adding SVM into the DTC method since DTC is capable of constant frequency switching. Since the switching affects the torque and flux, the number of ripples in flux and torque can be reduced. 2) After the ripples of flux and torque are reduced, the research will work on the robustness and stability of the proposed control technique. Since the number of sectors is the most influential factor to overcome disturbance and system uncertainties, the number of sectors will be modified. Eventually, a fast dynamic decoupled control that robustly responds to external disturbance and system uncertainties in the low-speed range can be achieved [20].

\section{Mathematical Modelling OF INDUCtion MOTOR}

The state-space model representation of a system can be mathematically written as the following equation:

$$
\left\{\begin{array}{l}
\dot{X}=\mathbf{A} X+\mathbf{B} U \\
Y=\mathbf{C} X
\end{array}\right.
$$

The state vector was represented as $X$, the input vector as $U$, and the output vector as $Y$.

According to [21], the state and the input vectors of an induction motor can be defined by the stator's current and the rotor flux components based on their stationary frame $(\alpha-\beta)$. Thus, it can be defined as:

$X=\left[\begin{array}{llll}i_{s \alpha} & i_{s \beta} & \phi_{r \alpha} & \phi_{r \beta}\end{array}\right]^{t}, U=\left[\begin{array}{lll}v_{s \alpha} & v_{s \beta}\end{array}\right]^{t}$, and $Y=\left[\begin{array}{ll}i_{s \alpha} & i_{s \beta}\end{array}\right]^{t}$.

$i_{s \alpha}$ and $i_{s \beta}$ are components of the stator's current in the $\alpha-\beta$ reference frame.

$\phi_{r \alpha}$ and $\phi_{r \beta}$ are components of the rotor's flux in the $\alpha$ - $\beta$ reference frame.

$v_{s \alpha}$ and $v_{s \beta}$ are components of the stator's voltage in the $\alpha-\beta$ reference frame.

Therefore, components of matrices in the state-space representation can be obtained by analyzing differential equations of the rotor flux and the stator current, as in the equation below.

$\begin{aligned} \mathbf{A} & =\left[\begin{array}{cccc}-\lambda & 0 & \frac{K}{T_{r}} & K \omega_{r} \\ 0 & -\lambda & -K \omega_{r} & \frac{K}{T_{r}} \\ \frac{L_{m}}{T_{r}} & 0 & -\frac{1}{T_{r}} & -\omega_{r} \\ 0 & \frac{L_{m}}{T_{r}} & \omega_{r} & -\frac{1}{T_{r}}\end{array}\right] ; \\ \mathbf{B} & =\left[\begin{array}{cc}\frac{1}{\sigma L_{s}} & 0 \\ 0 & \frac{1}{\sigma L_{s}} \\ 0 & 0 \\ 0 & 0\end{array}\right] ; \mathbf{C}=\left[\begin{array}{cccc}1 & 0 & 0 & 0 \\ 0 & 1 & 0 & 0\end{array}\right]\end{aligned}$

With $\lambda=\frac{R_{s}}{\sigma L_{s}}+\frac{1-\sigma}{\sigma T_{r}} ; K=\frac{1-\sigma}{\sigma L_{m}} ; \sigma=1-\frac{L_{m}^{2}}{L_{s} L_{r}} ; T_{r}=\frac{L_{r}}{R_{r}}$
Table I. Rated power and parameters of the used machine in simulation

\begin{tabular}{|l|l|}
\hline Rated power & $3 \mathrm{~kW}$ \\
\hline Rated speed & $1440 \mathrm{rpm}$ \\
\hline Pair pole & 2 \\
\hline Frequency & $50 \mathrm{~Hz}$ \\
\hline Line voltage & $220 / 380 \mathrm{~V}$ \\
\hline Phase current & $12.5 / 7.2 \mathrm{~A}$ \\
\hline Stator resistance & $2.2 \Omega$ \\
\hline Rotor resistance & $2.68 \Omega$ \\
\hline Stator inductance & $0.229 \mathrm{H}$ \\
\hline Rotor inductance & $0.229 \mathrm{H}$ \\
\hline Mutual inductance & $0.217 \mathrm{H}$ \\
\hline Moment of inertia & $0.047 \mathrm{~kg} . \mathrm{m}^{2}$ \\
\hline Viscous friction coefficient & $0.004 \mathrm{~N} . \mathrm{s} / \mathrm{rad}$ \\
\hline
\end{tabular}

The block diagram of the state-space model of induction motor can be seen in Fig. 1, while the lists of the rated power and parameters used in simulation can be seen in Table I.

\section{DTC FUNDAMENTALS}

The fundamental of DTC is to control the flux and the torque directly and separately within their respective hysteresis bands by selecting the optimal inverter switching states [22]. Coordinate transformation, current regulators, or PWM generators are unnecessary in DTC, while DTC provides an excellent torque control performance, especially in terms of a fast response [23].

\section{A. Stator Flux and Torque Estimation}

The measurement of flux and torque is estimated based on the stator currents and voltages. Based on the dynamics of induction motor in stator fixed reference frame, the stator flux can be written as in equation below [24] [25]:

$$
\bar{\phi}_{s}=\int_{0}^{t}\left(\bar{V}_{s}-R_{s} \bar{I}_{s}\right) d t
$$

Thus, the flux components in the $\alpha$ - $\beta$ coordinates can be defined as:

$$
\begin{aligned}
\phi_{s \alpha} & =\int_{0}^{t}\left(v_{s \alpha}-R_{s} i_{s \alpha}\right) d t \\
\phi_{s \beta} & =\int_{0}^{t}\left(v_{s \beta}-R_{s} i_{s \beta}\right) d t
\end{aligned}
$$

The stator flux module can be calculated based on the flux components in the $\alpha$ - $\beta$ coordinates, which can be mathematically defined as:

$$
\phi_{s}=\sqrt{\phi_{s \alpha}^{2}+\phi_{s \beta}^{2}}
$$

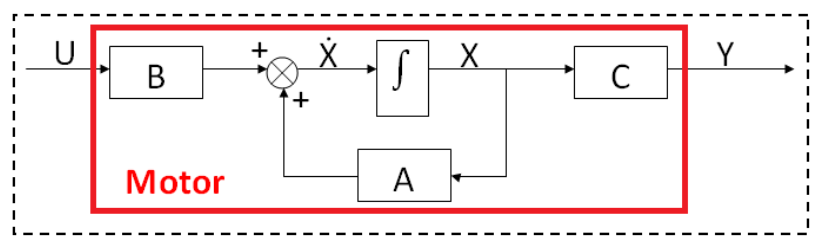

Fig. 1. Induction motor state-space mathematical model 
Table II. Basic DTC switching table

\begin{tabular}{|c||c|c|c|c|c|c|c|}
\hline$\Delta \phi_{s}$ & $\Delta T_{e}$ & $S_{1}$ & $S_{2}$ & $S_{3}$ & $S_{4}$ & $S_{5}$ & $S_{6}$ \\
\hline \hline \multirow{4}{*}{1} & 1 & 110 & 010 & 011 & 001 & 101 & 100 \\
& 0 & 111 & 000 & 111 & 000 & 111 & 000 \\
& -1 & 101 & 100 & 110 & 010 & 011 & 001 \\
\hline \multirow{3}{*}{0} & 1 & 010 & 011 & 001 & 101 & 100 & 110 \\
& 0 & 000 & 111 & 000 & 111 & 000 & 111 \\
& -1 & 001 & 101 & 100 & 110 & 010 & 011 \\
\hline
\end{tabular}

Meanwhile, the electromagnetic torque can be expressed as the difference of the product of the stator current and flux between different frames, as in the equation below:

$$
T_{e}=p\left(i_{s \beta} \phi_{s \alpha}-i_{s \alpha} \phi_{s \beta}\right)
$$

\section{B. Switching State Vector}

Inputs to the hysteresis comparators (controllers) are errors that resulted from the difference between reference values and estimated values. Meanwhile, outputs of the hysteresis controllers and flux locations determine the input selector of the switching table. The selector will then the suitable switching state vector. The switching table can be seen as in (Table II) [26]. This switching states vector $\left(S_{a} S_{b} S_{c}\right)$ generates eight position vectors $\left(\vec{V}_{1}, \vec{V}_{2}, \ldots, \vec{V}_{8}\right)$, where two of them correspond to the null vector $\left(S_{a} S_{b} S_{c}\right)=\left(\begin{array}{lll}1 & 1 & 1\end{array}\right)$ or $\left(\begin{array}{lll}0 & 0 & 0\end{array}\right)$ [27].

\section{Space Vector Modulation Algorithm}

The primary drawbacks of conventional DTC methods are the switching frequency and chattering effect (high level of ripples). As a consequence, the augmented system will have high harmonics of currents, acoustical noise, bad control performance especially when the system is being operated at a low-speed range. The principle of SVM is to predict the inverter voltage vector by projecting the reference vector $V_{s}^{*}$ between adjacent vectors corresponding to two non-zero switching states [28], as illustrated in Fig. 2 [29]. For sector 1:

$$
\begin{gathered}
V_{s}^{*} T_{z}=V_{1} T_{1}+V_{2} T_{2}+V_{0} T_{0} \\
T_{z}=T_{1}+T_{2}+T_{0}
\end{gathered}
$$

$T_{1}, T_{2}$, and $T_{0}$ are the corresponding application times of the voltage vectors respectively, while $T_{z}$ is the sampling time. The determination of times $T_{1}$ and $T_{2}$ corresponding to voltage vectors are obtained by simple projections below [30]:

$$
\begin{gathered}
T_{1}=\frac{T_{z}}{2 V_{d c}}\left(\sqrt{6} V_{s \beta}^{*}-\sqrt{2} V_{s \alpha}^{*}\right) \\
T_{2}=\sqrt{2} \frac{T_{z}}{V_{d c}} V_{s \alpha}^{*}
\end{gathered}
$$

$V_{d c}$ is the DC bus voltage. The switching times (duty cycles) can be calculated as in a mathematical expression below:

$$
T_{a_{O N}}=\frac{T_{z}-T_{1}-T_{2}}{2}
$$

$$
\begin{aligned}
& T_{b_{O N}}=T_{a_{O N}}+T_{1} \\
& T_{c_{O N}}=T_{b_{O N}}+T_{2}
\end{aligned}
$$

Table III presents a summary of the switching times (output) for each sector.

\section{Twelve SECTORS DTC SCHEME}

In the conventional six sectors DTC, two switching states per sector, which are $V_{i}$ and $V_{i+3}$, are not considered in the traditional 6-sector DTC. Thus, the torque control is ambiguous. Instead of moving the first sector from A sector shifting takes the first sector from $\left(\frac{11 \pi}{6}\right.$ to $\left.\frac{\pi}{6}\right)$, the sector shifts from (0 to $\left.\frac{\pi}{3}\right)$, creating a new switching table. It does, however, have two unused vectors per sector (i.e., $V_{i+2}$ and $\left.V_{i-1}\right)$, which creates an ambiguity in the flux control rather than the torque. Therefore, another strategy was developed which divides the circular flux locus into 12 sectors instead of 6, as shown in Fig. 3. Consequently, each sector uses all six states and ambiguity in torque and flux control can be avoided [31].

In the 12-sector DTC, the vector $V_{1}$ produces a large increase in flux and a small increase in torque for sector 12 . On the other hand, $V_{2}$ results in a large increase in torque and a small increase in flux. Therefore, the recent variations of small and large torque must now be defined [32]. As a result of this concept, the hysteresis band of the torque is divided into four. Then, the 12-sector switching table is provided in Table IV.

Several studies stated that the increase of the number of the sectors reduced the high ripples and current harmonics slightly [33] [34] [35]. Moreover, the addition of SVM algorithm provides good dynamics in high and low-speed range [36]. The diagram of torque and flux control based on the proposed 12sector DTC with SVM algorithm is represented in Fig. 4.

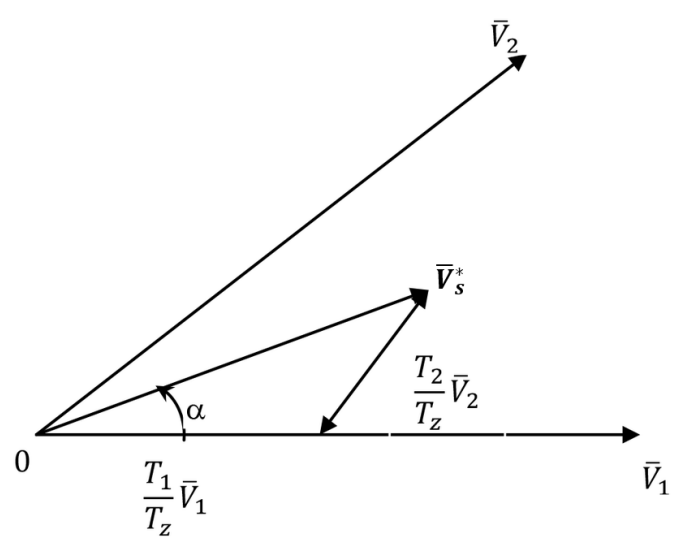

Fig. 2. Reference vector as a combination of adjacent vectors at sector 


\section{RESULTS AND DISCUSSION}

A comparison of the traditional DTC and the proposed twelve-sector SVM-DTC is presented in this paper. In MATLAB/Simulink, the DTC control algorithms for a three-phase $3 k W$ squirrel-cage induction motor drive were simulated. Table I shows the list of machine parameters used for simulation.

The test in Fig. 5 presented the starting up of the induction motor according to a low speed-step of $10 \mathrm{rad} / \mathrm{s}$. Then, a load of $10 \mathrm{~N} . \mathrm{m}$ was applied at $t_{1}=0.6 \mathrm{~s}$ and removed at $t_{2}=1.6 \mathrm{~s}$.

Both techniques had good dynamics when starting up, as shown in Fig. 5. The applied load disturbance was quickly rejected in speed regulation loop. The proposed SVM-DTC in Fig. 5 (b) maintained similar speed response as the conventional DTC in Fig. 5 (a). The transient response was identical in both schemes because the same PI speed controller was used.

Following that, the load-applied responses of the torque were illustrated. The speed controller initially operated the system at its physical limit. Compared to the conventional DTC in Fig. 5 (c), where the high torque ripples exceeded the hysteresis bound, the DTC-based electromagnetic torque control performance in Fig. 5 (d) had a reduced level of ripples due to the use of SVM. Moreover, according to the Fig. 6, the proposed SVM-DTC has a lower THD level $(33.50 \%)$ in Fig. 6 (d) compared to conventional DTC (64.53\%) in Fig. 6 (c).

Table III. Switching times for each sector

\begin{tabular}{|c||c|c|c|c|c|c|}
\hline$\Delta \phi_{s}$ & $S_{1}$ & $S_{2}$ & $S_{3}$ & $S_{4}$ & $S_{5}$ & $S_{6}$ \\
\hline \hline$S_{a}$ & $T_{b_{O N}}$ & $T_{a_{O N}}$ & $T_{a_{O N}}$ & $T_{c_{O N}}$ & $T_{b_{O N}}$ & $T_{c_{O N}}$ \\
\hline$S_{b}$ & $T_{a_{O N}}$ & $T_{c_{O N}}$ & $T_{b_{O N}}$ & $T_{b_{O N}}$ & $T_{c_{O N}}$ & $T_{a_{O N}}$ \\
\hline$S_{c}$ & $T_{c_{O N}}$ & $T_{b_{O N}}$ & $T_{c_{O N}}$ & $T_{a_{O N}}$ & $T_{a_{O N}}$ & $T_{b_{O N}}$ \\
\hline
\end{tabular}

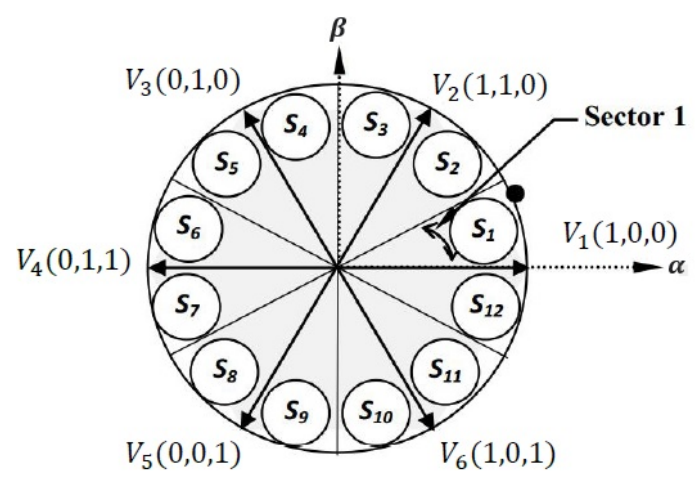

Fig. 3. Voltage space vector in twelve sectors case
Analysis and observations of the stator flux will be shown shortly in the following sentences. Both the conventional DTC and the proposed SVM-DTC showed sinusoid waveforms in their flux responses. However, the conventional DTC in Fig. 5 (e) showed a chopped sinusoid waveform of flux which indicates the high harmonics level, while SVM-DTC in Fig. 5 (f) showed a smoother one. It can be justified in the next Fig. 6 where the proposed SVM-DTC had a lower THD level $(75.36 \%)$ as in Fig. 6 (b) compared to the conventional DTC $(97.68 \%)$ in Fig. 6 (a).

The stator flux evolution, such as its magnitude and circular trajectory, can also be observed in the simulation results. For example, according to stator flux magnitude, the ripples exceeded the hysteresis bounds, which can be seen in Fig. 5 (i). Moreover, due to the changing of the zone, the flux initially takes a few steps before achieving the referenced flux magnitude (1 $W b)$ (Fig. 5 (k). Also, the stator flux components show an acceptable waveform but high level of ripples. The proposed SVM-DTC showed reduced level of flux ripples, faster magnitude tracking at the initial state, and better components waveform than the conventional DTC. This is due to a better zone selection operation of the stator flux vector in the proposed technique. The zone selection operation can be seen in Fig. 5 (1).

\section{CONCLUSION}

The design and simulation of improved DTC had been conducted for the induction motor system. Overall, the proposed method can make the system perform dynamically well while being operated at a low-speed range. When a load was applied suddenly to the system's simulation, the system responded well, which indicates faster dynamics. The novel improvisation technique was also proven to give finer torque pulsation and flux distortion. The flux ripples were reduced, magnitude tracking had a faster start-up, and waveforms had better components than the system response of conventional DTC. Based on the experiment results, a system implemented with the proposed method was highly-efficient and precise; the addition of the SVM algorithm and number of sectors plays a critical role in the augmented system's performance.

\section{REFERENCES}

[1] V. Sousa Santos, J. J. Cabello Eras, A. Sagastume Gutierrez, and M. J. Cabello Ulloa, "Assessment of the energy efficiency estimation methods on induction motors considering real-time monitoring," Measurement, vol. 136, pp. 237-247, Mar. 2019.

[2] F. Altun, S. A. Tekin, S. Gürel, and M. Cernat, "Design and Optimization of Electric Cars. A Review of Technological Advances," in 2019 8th International Conference on Renewable Energy Research and Applications (ICRERA), Nov. 2019, pp. 645-650.

[3] H. Maghfiroh, I. Iftadi, and A. Sujono, "Speed Control of Induction Motor using LQG," Journal of Robotics and Control (JRC), vol. 2, no. 6, pp. 565-570, Nov. 2021.

[4] J. Faiz, V. Ghorbanian, and G. Joksimovic, Fault Diagnosis of Induction Motors. $\quad$ IET Digital Library, Aug. 2017. 
Table IV. Switching table for the proposed twelve sectors DTC

\begin{tabular}{|c||c||c|c|c|c|c|c|c|c|c|c|c|c|}
\hline$\Delta \phi_{s}$ & $\Delta T_{e}$ & $S_{1}$ & $S_{2}$ & $S_{3}$ & $S_{4}$ & $S_{5}$ & $S_{6}$ & $S_{7}$ & $S_{8}$ & $S_{9}$ & $S_{10}$ & $S_{11}$ & $S_{12}$ \\
\hline \hline \multirow{3}{*}{1} & 2 & $V_{2}$ & $V_{3}$ & $V_{3}$ & $V_{4}$ & $V_{4}$ & $V_{5}$ & $V_{5}$ & $V_{6}$ & $V_{6}$ & $V_{1}$ & $V_{1}$ & $V_{2}$ \\
& 1 & $V_{2}$ & $V_{2}$ & $V_{3}$ & $V_{3}$ & $V_{4}$ & $V_{4}$ & $V_{5}$ & $V_{5}$ & $V_{6}$ & $V_{6}$ & $V_{1}$ & $V_{1}$ \\
& -1 & $V_{1}$ & $V_{1}$ & $V_{2}$ & $V_{2}$ & $V_{3}$ & $V_{3}$ & $V_{4}$ & $V_{4}$ & $V_{5}$ & $V_{5}$ & $V_{6}$ & $V_{6}$ \\
& -2 & $V_{6}$ & $V_{1}$ & $V_{1}$ & $V_{2}$ & $V_{2}$ & $V_{3}$ & $V_{3}$ & $V_{4}$ & $V_{4}$ & $V_{5}$ & $V_{5}$ & $V_{6}$ \\
\hline \hline \multirow{3}{*}{0} & 2 & $V_{3}$ & $V_{4}$ & $V_{4}$ & $V_{5}$ & $V_{5}$ & $V_{6}$ & $V_{6}$ & $V_{1}$ & $V_{1}$ & $V_{2}$ & $V_{2}$ & $V_{3}$ \\
& 1 & $V_{4}$ & $V_{4}$ & $V_{5}$ & $V_{5}$ & $V_{6}$ & $V_{6}$ & $V_{1}$ & $V_{1}$ & $V_{2}$ & $V_{2}$ & $V_{3}$ & $V_{3}$ \\
& -1 & $V_{5}$ & $V_{5}$ & $V_{6}$ & $V_{6}$ & $V_{1}$ & $V_{1}$ & $V_{2}$ & $V_{2}$ & $V_{3}$ & $V_{3}$ & $V_{4}$ & $V_{4}$ \\
& -2 & $V_{5}$ & $V_{6}$ & $V_{6}$ & $V_{1}$ & $V_{1}$ & $V_{2}$ & $V_{2}$ & $V_{3}$ & $V_{3}$ & $V_{4}$ & $V_{4}$ & $V_{5}$ \\
\hline
\end{tabular}

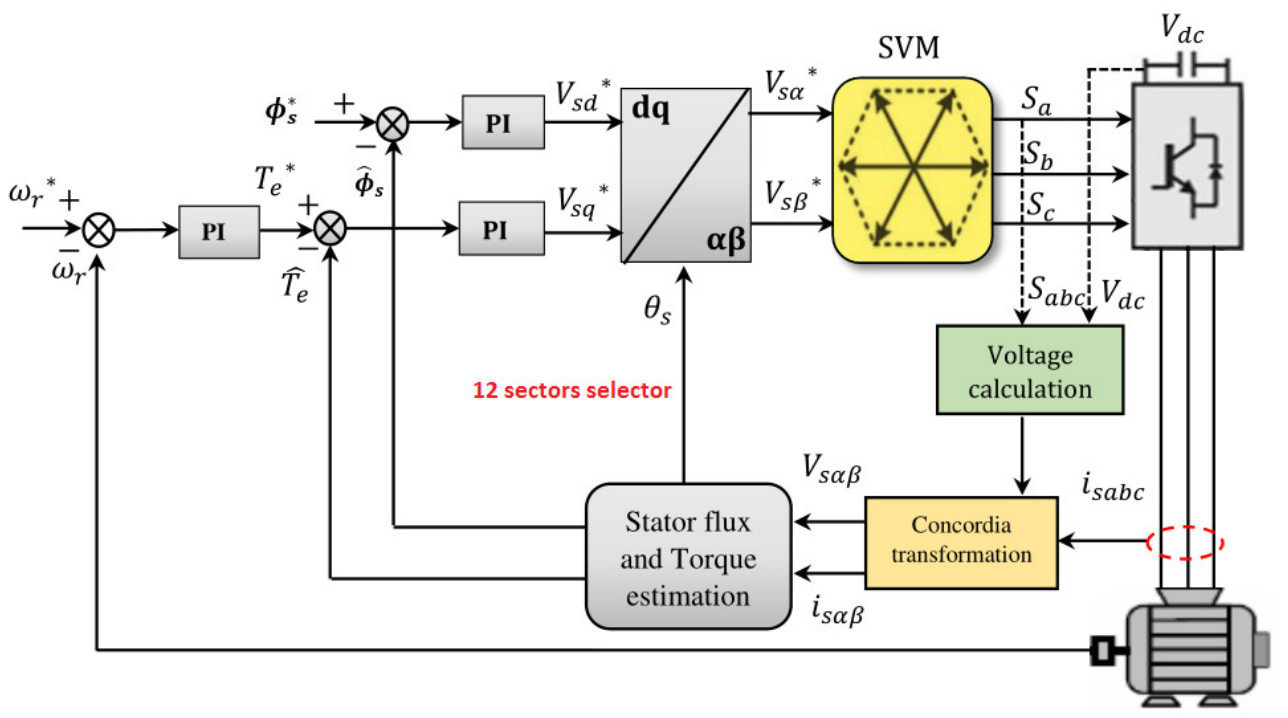

Fig. 4. The proposed control scheme

[5] Y. Zahraoui, A. Bennassar, M. Akherraz, and A. Essalmi, "Indirect Vector Control of Induction Motor using an Extended Kalman Observer and Fuzzy Logic Controllers," in 2015 3rd International Renewable and Sustainable Energy Conference (IRSEC), Dec. 2015, pp. 1-6.

[6] Y. Zahraoui and M. Akherraz, Kalman Filtering Applied to Induction Motor State Estimation. IntechOpen, Jun. 2020.

[7] M. Aktas, K. Awaili, M. Ehsani, and A. Arisoy, "Direct torque control versus indirect field-oriented control of induction motors for electric vehicle applications," Engineering Science and Technology, an International Journal, vol. 23, no. 5, pp. 1134-1143, Oct. 2020.

[8] A. Ma'arif and N. R. Setiawan, "Control of DC Motor Using Integral State Feedback and Comparison with PID: Simulation and Arduino Implementation," Journal of Robotics and Control (JRC), vol. 2, no. 5, pp. 456-461, Sep. 2021.

[9] Y. Zahraoui, M. Akherraz, and A. Ma'arif, "A Comparative Study of Nonlinear Control Schemes for Induction Motor Operation Improvement," International Journal of Robotics and Control Systems, vol. 2, no. 1, pp. 1-17, 2022.

[10] Y. Zahraoui, M. Akherraz, C. Fahassa, and S. Elbadaoui, "Robust Control of Sensorless Sliding Mode Controlled Induction Motor Drive facing a Large Scale Rotor Resistance Variation," in Proceedings of the 4th International Conference on Smart City Applications, ser. SCA '19. New York, NY, USA: Association for Computing Machinery, Oct. 2019, pp. $1-6$.

[11] A. Arias, E. Ibarra, E. Trancho, R. Griñó, I. Kortabarria, and J. Caum, "Comprehensive high speed automotive SM-PMSM torque control stability analysis including novel control approach," International Journal of Electrical Power \& Energy Systems, vol. 109, pp. 423-433, Jul. 2019.
[12] F. B. Salem, Direct Torque Control Strategies of Electrical Machines, Jan. 2021. [Online]. Available: https://www.intechopen.com/books/8686

[13] Y. Cho, Y. Bak, and K.-B. Lee, "Torque-Ripple Reduction and Fast Torque Response Strategy for Predictive Torque Control of Induction Motors," IEEE Transactions on Power Electronics, vol. 33, no. 3, pp. 2458-2470, Mar. 2018.

[14] R. Chen, J. Niu, H. Gui, Z. Zhang, F. Wang, L. M. Tolbert, D. J. Costinett, B. J. Blalock, and B. B. Choi, "Modeling, Analysis, and Reduction of Harmonics in Paralleled and Interleaved Three-Level Neutral Point Clamped Inverters With Space Vector Modulation," IEEE Transactions on Power Electronics, vol. 35, no. 4, pp. 4411-4425, Apr. 2020.

[15] B. Kirankumar, Y. V. S. Reddy, and M. Vijayakumar, "Multilevel inverter with space vector modulation: intelligence direct torque control of induction motor," IET Power Electronics, vol. 10, no. 10, pp. 1129-1137, 2017.

[16] H. Benbouhenni, "Fuzzy speed controller of induction machine with 36 sectors DTC based ANFIS hysteresis comparator," Majlesi Journal of Mechatronic Systems, vol. 8, no. 3, pp. 1-8, Sep. 2019.

[17] A. Sivaprakasam, "A new approach to reduce torque ripple and noise in twelve-sector based direct torque controller fed permanent magnet synchronous motor drive: simulation and experimental results," Noise Control Engineering Journal, vol. 65, no. 6, pp. 531-548, Nov. 2017.

[18] A. Pal, G. D. Srivastava, and R. D. Kulkarni, "Simulation of Sensorless Speed Control of Induction Motor Using Direct Torque Control Technique Employing Five Level Torque Comparator and Twelve Sector Method," in 2019 International Conference on Nascent Technologies in Engineering (ICNTE), Jan. 2019, pp. 1-6.

[19] Y. Zahraoui, M. Akherraz, and S. Elbadaoui, “ Fuzzy Logic Speed Control 


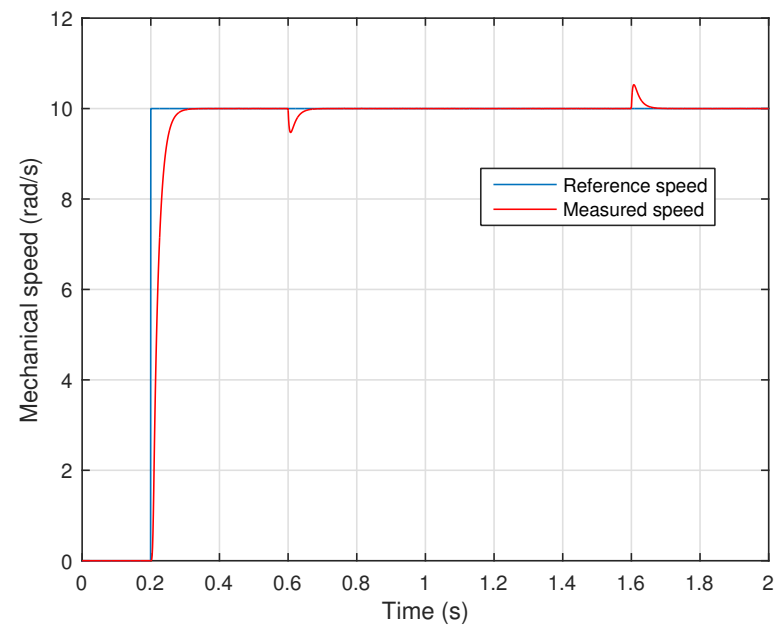

(a) Conventional DTC: mechanical speed

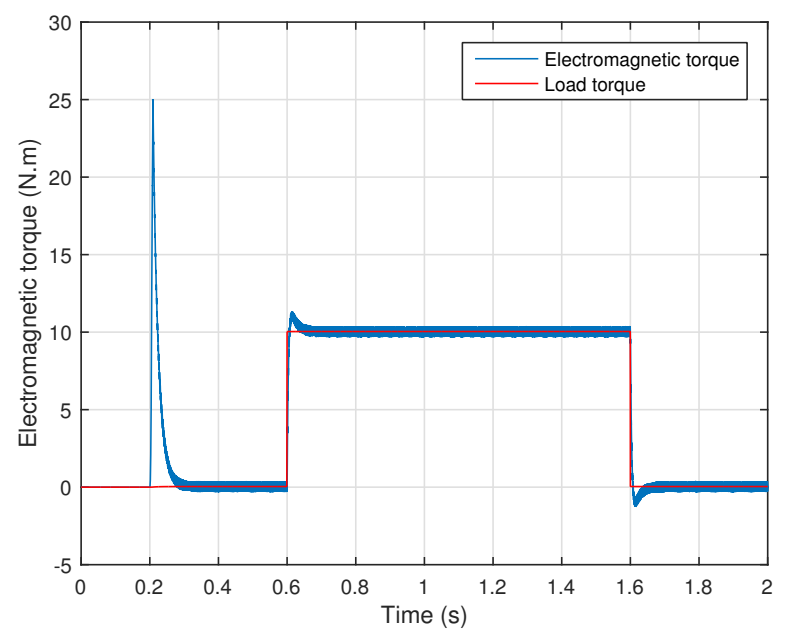

(c) Conventional DTC: electromagnetic torque

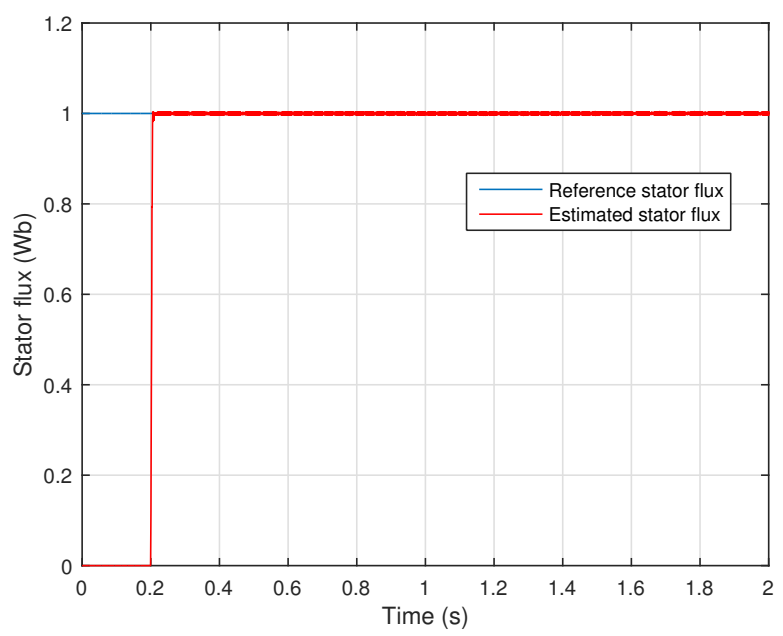

(e) Conventional DTC: stator flux

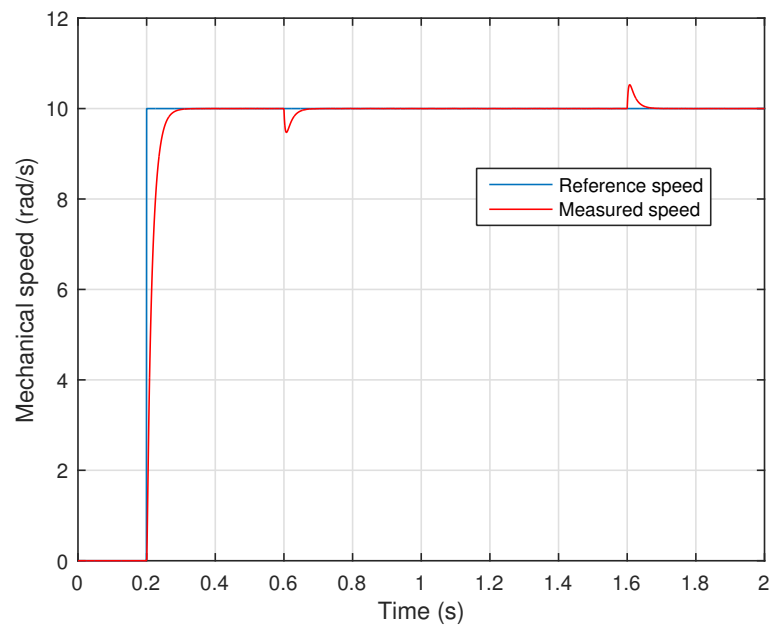

(b) Proposed DTC: mechanical speed

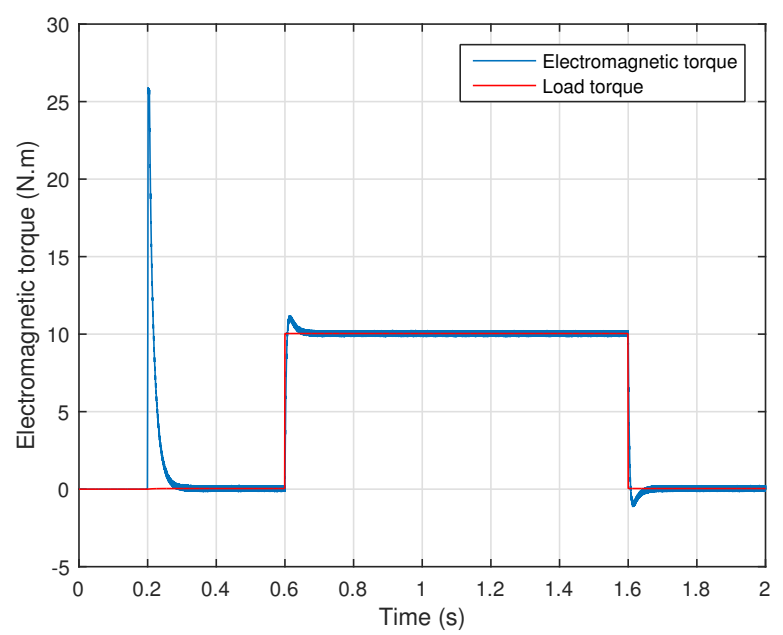

(d) Proposed DTC: electromagnetic torque

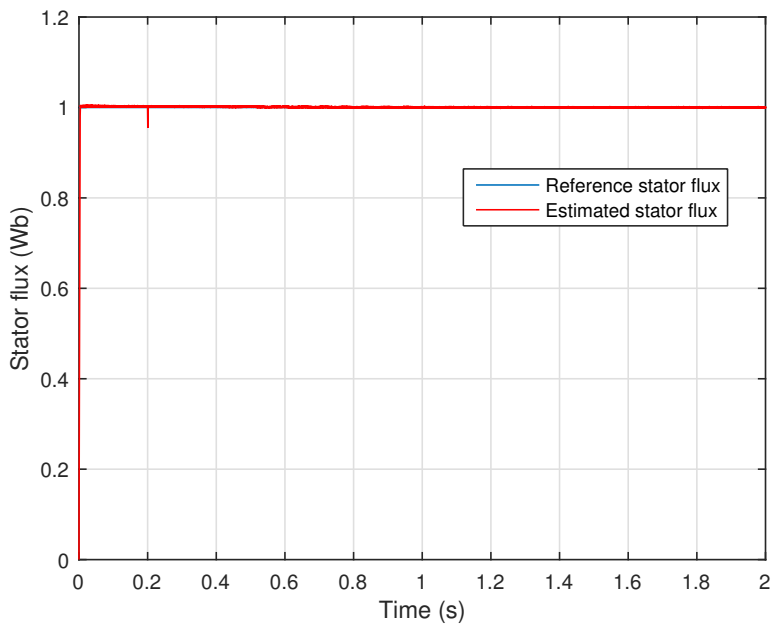

(f) Proposed DTC: stator flux 


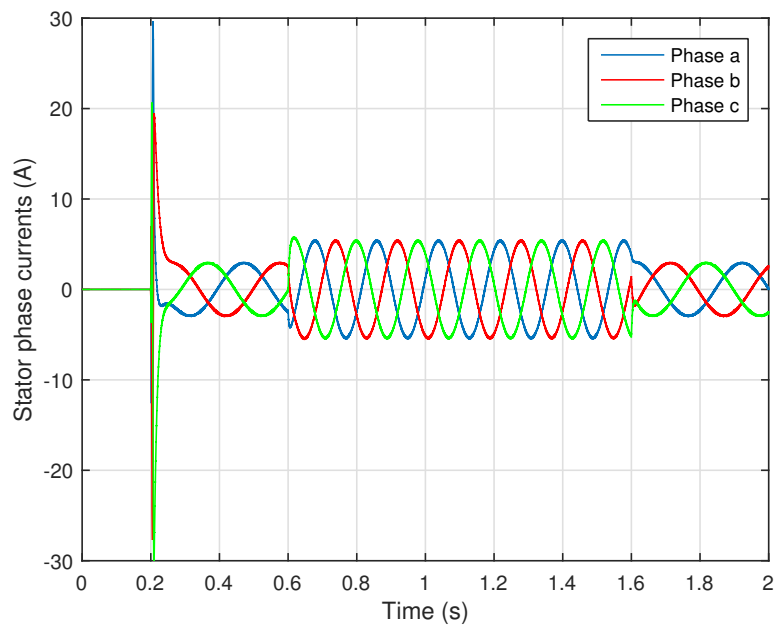

(g) Conventional DTC: stator phase current

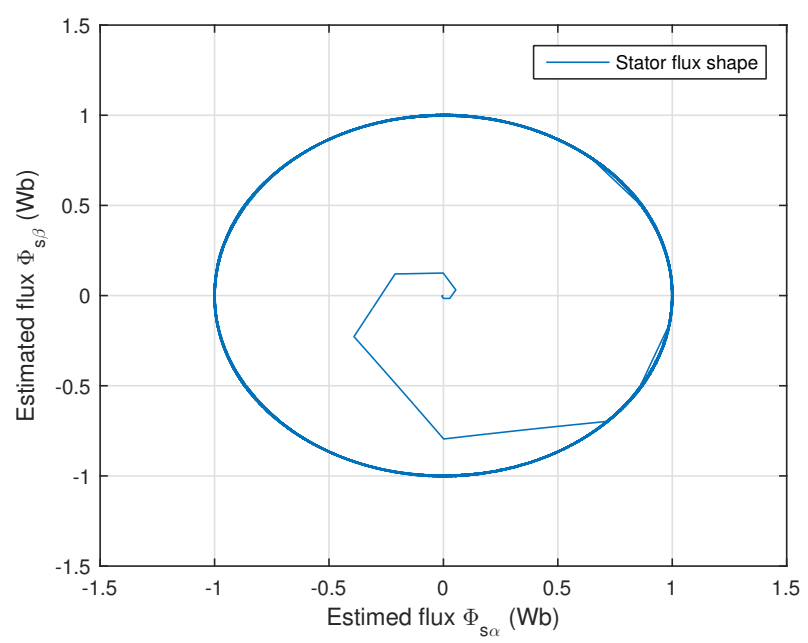

(i) Conventional DTC: flux circular trajectory

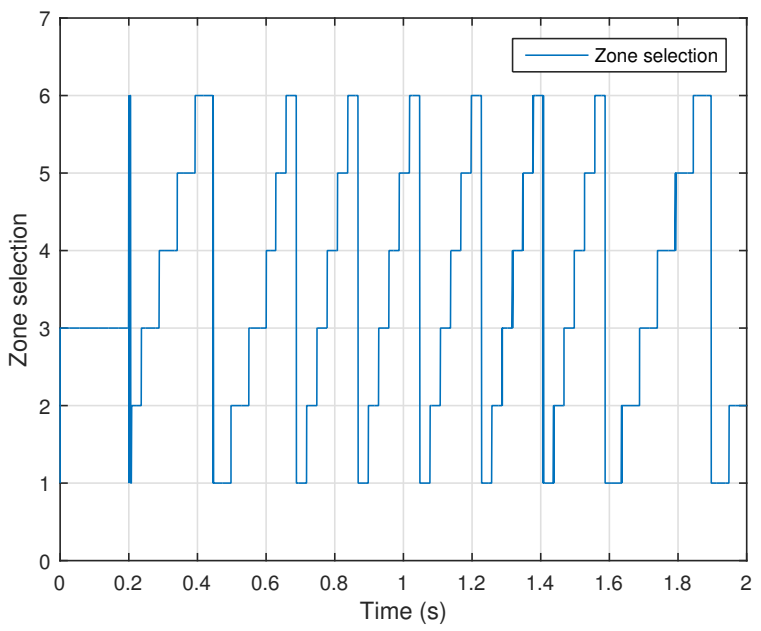

(k) Conventional DTC: zone selection

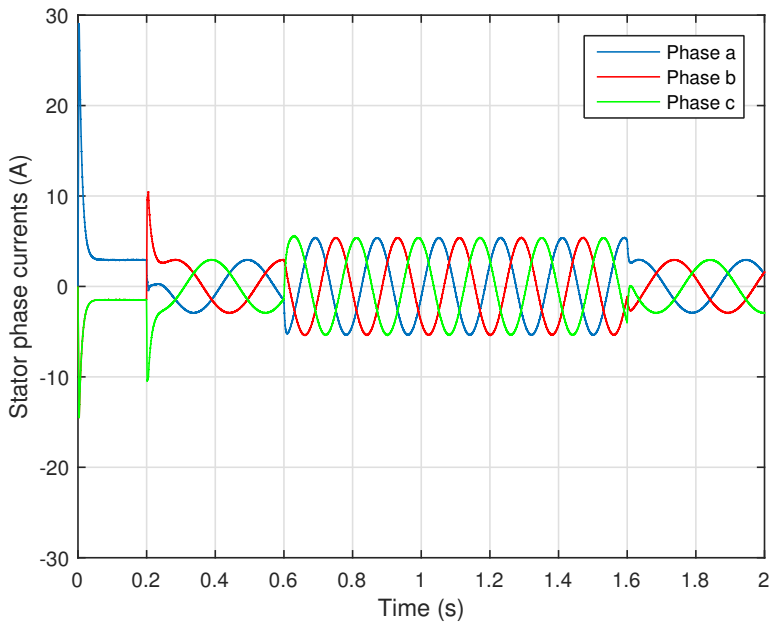

(h) Proposed DTC: stator phase current

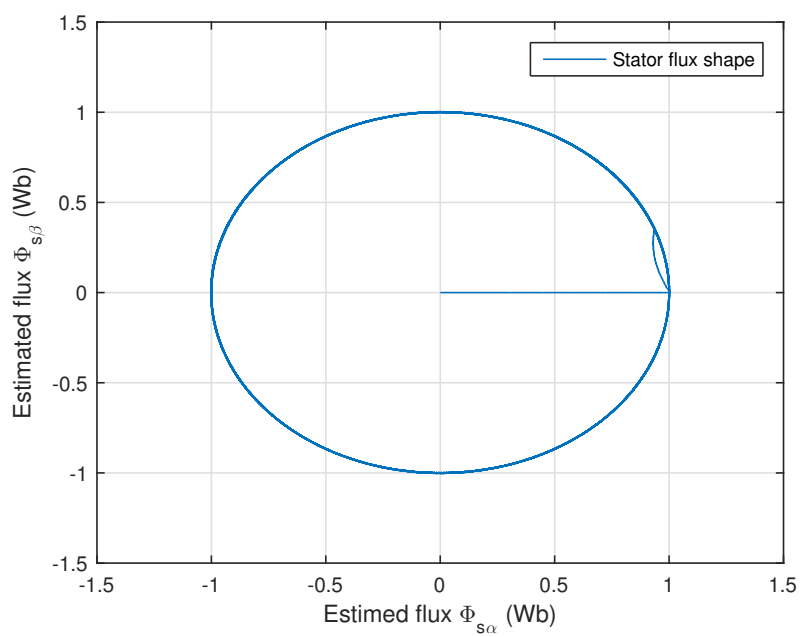

(j) Proposed DTC: flux circular trajectory

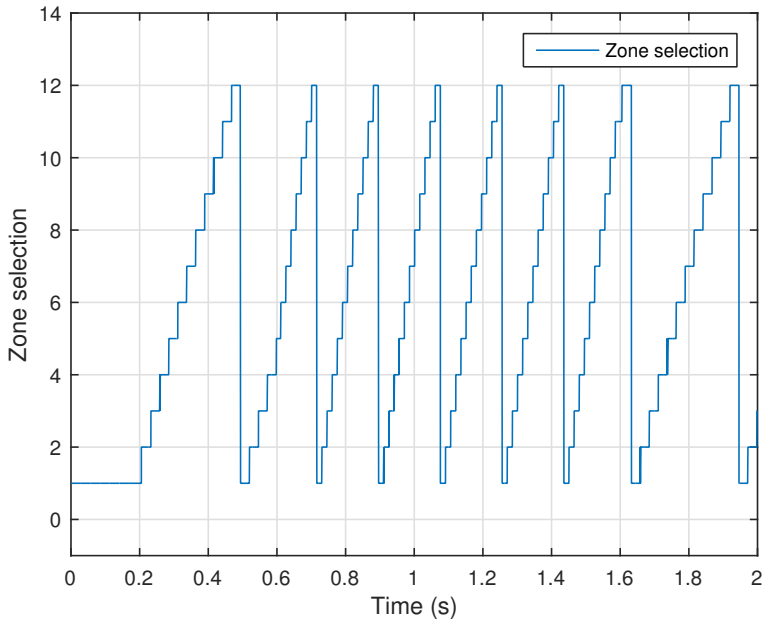

(1) Proposed DTC: zone selection

Fig. 5. DTC performance improvement: low-speed region 


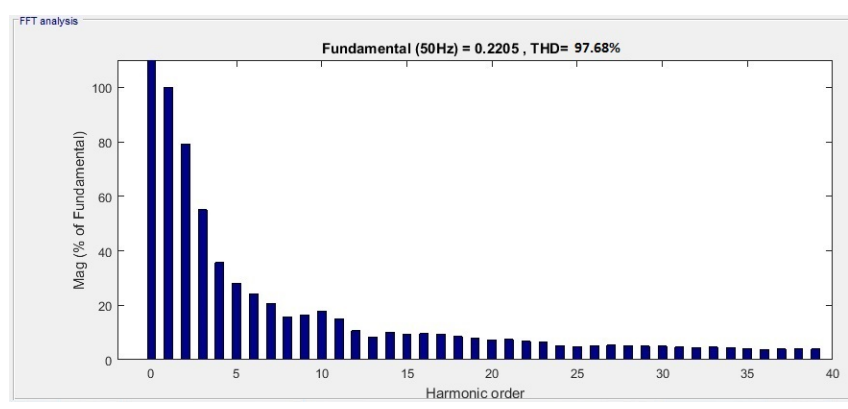

(a) Conventional DTC: flux THD

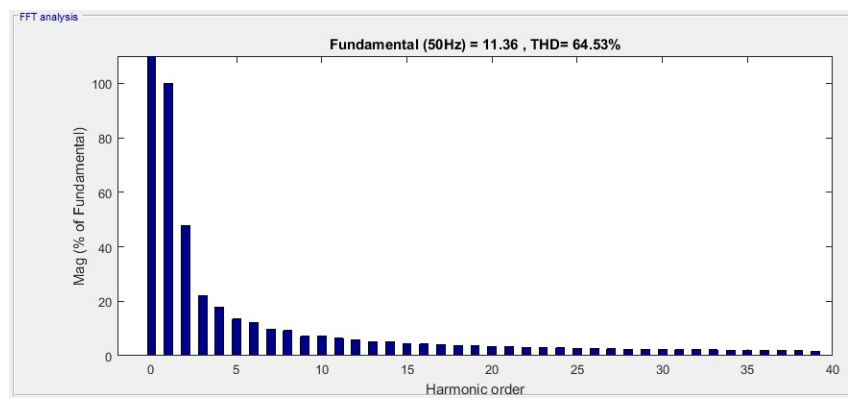

(c) Conventional DTC: torque THD

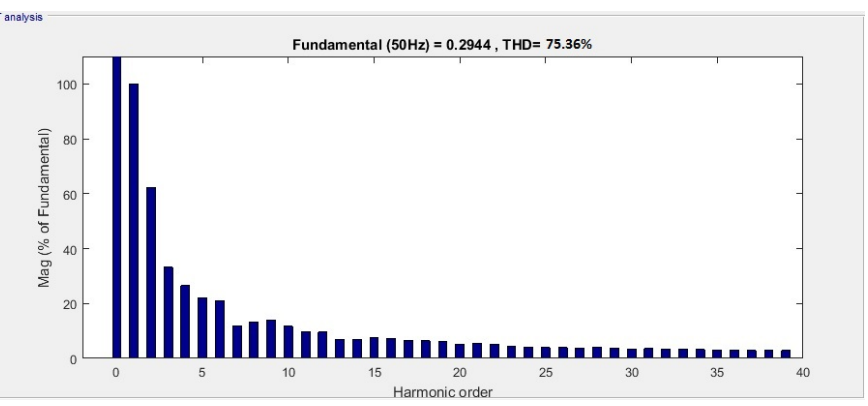

(b) Proposed DTC: flux THD

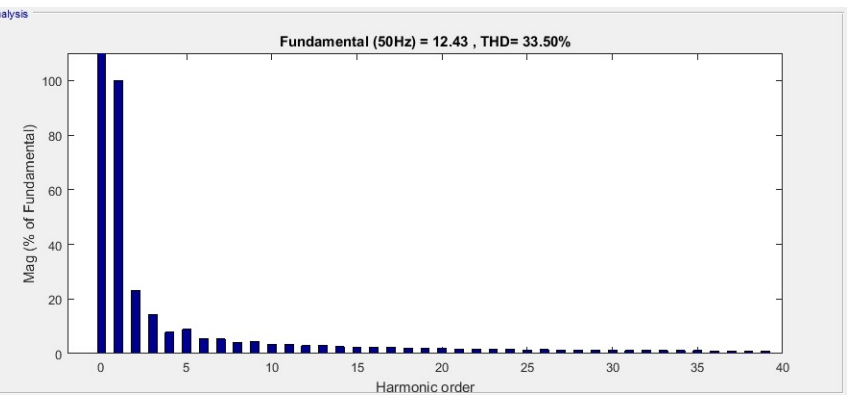

(d) Proposed DTC: torque THD

Fig. 6. Flux and torque THD improvement

and Adaptation Mechanism-Based Twelve Sectors DTC to Improve the Performance of a Sensorless Induction Motor Drive," International Journal on Electrical Engineering \& Informatics, vol. 13, no. 3, pp. 508529, 2021.

[20] A. Balashanmugham, M. Mockaisamy, and S. Murugesan, Torque Ripple Reduction in DTC Induction Motor Drive. IntechOpen, Oct. 2020, publication Title: Direct Torque Control Strategies of Electrical Machines.

[21] F. N. Sarapulov, V. E. Frizen, E. L. Shvydkiy, and I. A. Smol'yanov, "Mathematical Modeling of a Linear-Induction Motor Based on Detailed Equivalent Circuits," Russian Electrical Engineering, vol. 89, no. 4, pp. 270-274, Apr. 2018.

[22] N. El Ouanjli, S. Motahhir, A. Derouich, A. El Ghzizal, A. Chebabhi, and M. Taoussi, "Improved DTC strategy of doubly fed induction motor using fuzzy logic controller," Energy Reports, vol. 5, pp. 271-279, Nov. 2019.

[23] I. Nouira El Badsi, B. El Badsi, and A. Masmoudi, "DTC strategies for three-switch three-phase inverter-fed induction motor drives," COMPEL The international journal for computation and mathematics in electrical and electronic engineering, vol. 37, no. 6, pp. 2176-2194, Jan. 2018.

[24] A. Shinohara and K. Yamamoto, "Estimation Error Analysis of Stator Flux Observer for DTC-Based PMSM Drives," in 2018 International Power Electronics Conference (IPEC-Niigata 2018 -ECCE Asia), May 2018, pp. 1308-1314.

[25] C. Fahassa, M. Akherraz, and Y. Zahraoui, "ANFIS-based hysteresis comparators with intelligent dual observer and speed controller of a direct torque control," International Journal of Powertrains, vol. 9, no. 1-2, p. $150,2020$.

[26] D. Mohan, X. Zhang, and G. H. Beng Foo, "Generalized DTC Strategy for Multilevel Inverter Fed IPMSMs With Constant Inverter Switching Frequency and Reduced Torque Ripples," IEEE Transactions on Energy Conversion, vol. 32, no. 3, pp. 1031-1041, Sep. 2017.

[27] J. K. Pandit, M. V. Aware, R. Nemade, and Y. Tatte, "Simplified Implementation of Synthetic Vectors for DTC of Asymmetric Six-Phase Induction Motor Drives," IEEE Transactions on Industry Applications, vol. 54, no. 3, pp. 2306-2318, May 2018.

[28] A. Ammar, A. Benakcha, and A. Bourek, "Closed loop torque SVM-DTC based on robust super twisting speed controller for induction motor drive with efficiency optimization," International Journal of Hydrogen Energy, vol. 42, no. 28, pp. 17940-17 952, Jul. 2017.

[29] Y. Zahraoui, M. Akherraz, C. Fahassa, and S. Elbadaoui, "Induction Motor Harmonic Reduction using Space Vector Modulation Algorithm," Bulletin of Electrical Engineering and Informatics, vol. 9, no. 2, pp. 452-465, Apr. 2020.

[30] Y. Zahraoui, C. Fahassa, M. Akherraz, and A. Bennassar, "Sensorless Vector Control of Induction Motor using an EKF and SVPWM Algorithm," in 2016 5th International Conference on Multimedia Computing and Systems (ICMCS), Sep. 2016, pp. 588-593.

[31] Y. Zahraoui, M. Akherraz, and C. Fahassa, "Induction Motor Performance Improvement using Twelve Sectors DTC and Fuzzy Logic Speed Regulation," WSEAS Transactions on Systems and Control, vol. 15, pp. 47-56, 2020.

[32] A. Sahu, K. B. Mohanty, and R. N. Mishra, "Improved Sector-Based DTC-SVM for Induction Motor Drive Using Hybrid Fuzzy-PI Controller," in Advances in Electrical Control and Signal Systems, ser. Lecture Notes in Electrical Engineering, G. Pradhan, S. Morris, and N. Nayak, Eds. Singapore: Springer, 2020, pp. 415-428.

[33] Z. Wu, J. Zhou, G. Zheng, T. Li, and Z. Zhu, "New Eighteen-sector Direct Torque Control Based on Duty Ratio Modulation," Journal of Physics: Conference Series, vol. 1449, p. 012033, Jan. 2020.

[34] A. Ghamri, R. Boumaaraf, M. T. Benchouia, H. Mesloub, A. Goléa, and N. Goléa, "Comparative study of ANN DTC and conventional DTC controlled PMSM motor," Mathematics and Computers in Simulation, vol. 167, pp. 219-230, Jan. 2020.

[35] H. Mesloub, R. Boumaaraf, M. T. Benchouia, A. Goléa, N. Goléa, and K. Srairi, "Comparative study of conventional DTC and DTC_svm based control of PMSM motor - Simulation and experimental results," Mathematics and Computers in Simulation, vol. 167, pp. 296-307, Jan. 2020.

[36] N. H. Viet and N. PARASCHIV, "An Investigation on Twelve Sectors Direct Torque Control for Induction Motors fed by Matrix Converter," in 2020 12th International Conference on Electronics, Computers and Artificial Intelligence (ECAI), Jun. 2020, pp. 1-5. 